\title{
Adoption of Web-Based Spatial Tools by Agricultural Producers: Conversations with Seven Northeastern Ontario Farmers Using the GeoVisage Decision Support System
}

\author{
Daniel H. Jarvis ${ }^{1, *}$, Mark P. Wachowiak ${ }^{2}$, Dan F. Walters ${ }^{3}$ and John M. Kovacs ${ }^{3}$ \\ 1 Schulich School of Education, Nipissing University, North Bay, ON P1B8L7, Canada \\ 2 Department of Computer Science and Mathematics, Nipissing University, North Bay, ON P1B8L7, Canada; \\ markw@nipissingu.ca \\ 3 Department of Geography, Nipissing University, North Bay, ON P1B8L7, Canada; \\ danw@nipissingu.ca (D.F.W.); johnmk@nipissingu.ca (J.M.K.) \\ * Correspondence: danj@nipissingu.ca; Tel.: +1-705-474-3461 (ext. 4445)
}

Received: 9 June 2017; Accepted: 2 August 2017; Published: 8 August 2017

\begin{abstract}
This paper reports on the findings of a multi-site qualitative case study research project designed to document the utility and perceived usefulness of weather station and imagery data associated with the online resource GeoVisage among northeastern Ontario farmers. Interviews were conducted onsite at five participating farms (three dairy, one cash crop, and one public access fruit/vegetable) in 2014-2016, and these conversations were transcribed and returned to participants for member checking. Interview data was then entered into Atlas.ti software for the purpose of qualitative thematic analysis. Fifteen codes emerged from the data and findings center around three overarching themes: common uses of weather station data (e.g., air/soil temperature, rainfall); the use of GeoVisage Imagery data/tools (e.g., acreage calculations, remotely sensed imagery); and future recommendations for the online resource (e.g., communication, secure crop imagery, mobile access). Overall, weather station data and tools freely accessible through the GeoVisage site were viewed as representing a timely, positive, and important addition to contemporary agricultural decision-making in northeastern Ontario farming.
\end{abstract}

Keywords: GIS technology; precision agriculture; web-based access; weather; weather station; decision support

\section{Introduction}

For millennia, farming has been characterized by compound and unpredictable factors. Aubert et al. [1] discuss this complexity and the perennial uncertainty of crop farming as follows:

A crop farmer needs to consider a variety of parameters such as crop yield, availability of water and nutrients, and a range of site- and soil-specific factors to optimize the plant treatment (e.g., application of fertilizer, pesticides, or irrigation). A high variability of these parameters within a single field further complicates the optimization of the plant treatment. (p. 510)

Agriculture, in terms of both the cash cropping and the livestock industry, has been under increasing pressure from both governmental agencies and the general public to change traditional farming practices to minimize adverse environmental and social effects. Agricultural decision support systems (DSSs) have been designed to help farmers implement more sustainable practices by aiding 
them in optimizing farming practices to maximize economic efficiency and to reduce impacts off the farm-good stewardship. Over the past 40 years, researchers have speculated that it was only a matter of time before agricultural decision support systems became an essential tool in the management of agricultural operations. Despite these systems being readily available and affordable [2-8], implementation at the farm-scale has not met expectations [9-12]. The theoretical rationale for supporting decision support technology in the 1970s and 1980s was based on cognitive science. It was thought that computation could overcome the limitations of human ability to process information and to make rational decisions based on scientific evidence. McCown [13] argues that this information-processing view of human decision-making has been replaced by "more 'ecological' theories ... in which there is an emphasis on sense-making and experimental learning in complex, lived-in environments" (p. 190). This idea represents a fundament shift from developing decision support systems based on scientific evidence to one that also emphasizes social values and constructs. There needs to be less emphasis on the implementation problem and more attention on how to achieve mutual understanding between developers and practitioners. Less emphasis should be placed on recommendations to farmers, and "more about facilitation of decision process adaptation" (p. 181). Decisional guidance is defined by Silver [14] (p. 107) as "how a decision support system enlightens or sways its users as they structure and execute their decision making process-that is, as they choose among and use the system's functional capabilities."

In an effort to improve the adoption of decision support systems among the agricultural industry, designers are increasingly taking a more participatory approach. The benefit of a participatory approach is that the end user can assess the usefulness of the tool. Several studies suggest that the adoption of a participatory approach that integrates designers and users in the development of agricultural decision support tools will reduce the implementation gap of these decision support tools $[15,16]$. The key to user acceptance of this technology is the perceived usefulness of the tool and the farmer's purpose or task. Rose et al. [17] identify fifteen factors affecting use of agricultural decision support tools, including relevance to producers, reliability, peer endorsement, ease of use, and cost, among others. Ultimately, implementation is dependent upon the perception that the decisional guidance tool provides a high value of return with limited risk $[13,18,19]$.

The development of online video tutorials, training programs, and access to knowledgeable practitioners can help improve implementation [15]. However, Jakku and Thorburn [16] suggest that social learning is a fundamental component of the participatory approach. Collaboration can enhance opportunities for innovation. The qualitative research described in this paper provided the opportunity to directly interview a number of northeastern Ontario farmers to assess whether, and in what ways, they have adopted a freely available, locally developed decision support systems involving farm-based weather stations and the related, freely accessible online resource known as GeoVisage. Such qualitative investigations based upon case studies are valuable for assessing the extent to which new precision agriculture technologies are being adopted, and underscore the importance of participatory approaches when designing technology tools for agricultural producers. First, we shall provide some background information regarding the northeastern Ontario weather stations and the development of the GeoVisage decision support system (Section 2), and then we will elaborate on the case study that was conducted with local agricultural producers and the related findings and conclusions (Sections 3-6).

\section{GeoVisage and the Northeastern Ontario Weather Stations}

GeoVisage [20] is a web-based decision support tool that represents a multi-year, multi-disciplinary project that has been funded by the Northern Ontario Heritage Fund Corporation, the Ontario Soil and Crop Improvement Association, and Nipissing University [21]. GeoVisage was designed for use by northeastern Ontario agricultural producers to support key decisions in the increasingly important emerging agricultural regions of Temiskaming Shores, Verner, and Cochrane. To collect data for the GeoVisage system, starting in May 2009, Nipissing University has installed and has maintained seven weather stations throughout northeastern Ontario (see Figure 1). 


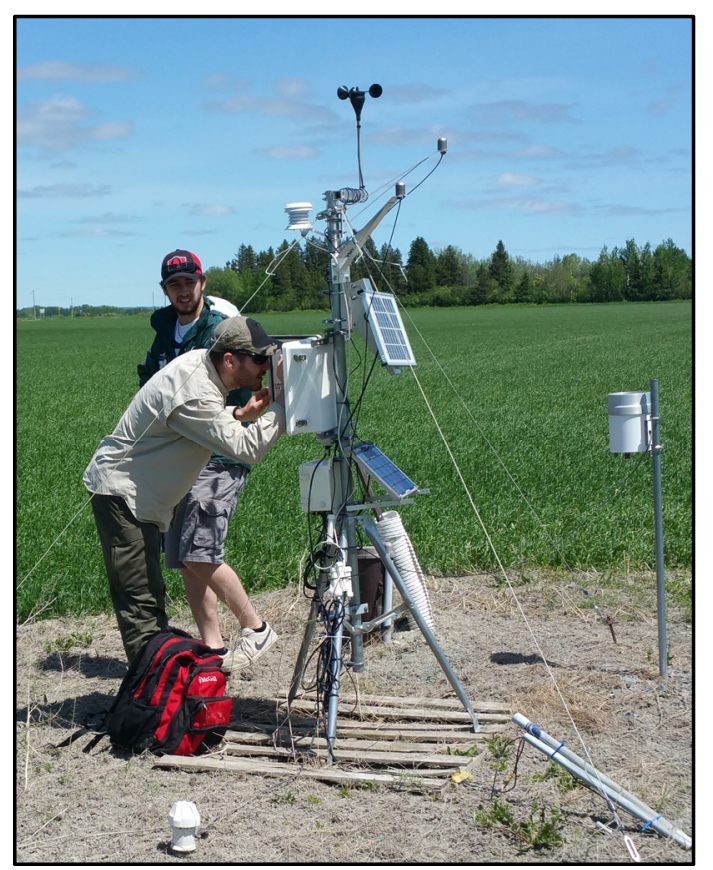

Figure 1. One of the many weather stations maintained for the GeoVisage system. This HOBO U30 station, located in Temiskaming Shores, has been actively collecting data since 3 July 2009.

Five additional stations have since been erected (Figure 2) and will soon be integrated into the system. It is important to note that local producers first contacted the university hoping to help them collect weather data. Prior to the weather station network, the local producers had to rely on federal government (Environment Canada) stations that, for the most part, are located at airports (e.g., North Bay (NB) \& Earlton stations) which are often not representative of local conditions (e.g., NB airport is located on an escarpment away from Lake Nipissing). Most importantly, there are very few weather stations in northeastern Ontario; for example, prior to 2009, the West Nipissing agricultural district (including Verner and Sturgeon Falls) had to rely on the Sudbury and North Bay Environment Canada weather stations which are approximately $80 \mathrm{~km}$ west and $50 \mathrm{~km}$ east of their district, respectively (see Figure 2).

Each station collects data on its microclimates, including such vital real-time weather information as air and soil temperature, relative humidity, wind speed, leaf wetness, and photosynthetically active radiation. The GeoVisage system also calculates growing-degree-days and crop-heating-unit values to assist farmers in planning [22]. These data are made available via an interactive website. The system provides four main services: real-time data acquisition and display, in-depth visualization of comparative and historical data, imagery obtained from a variety of modalities, and sharing of geo-referenced digital photographs. 


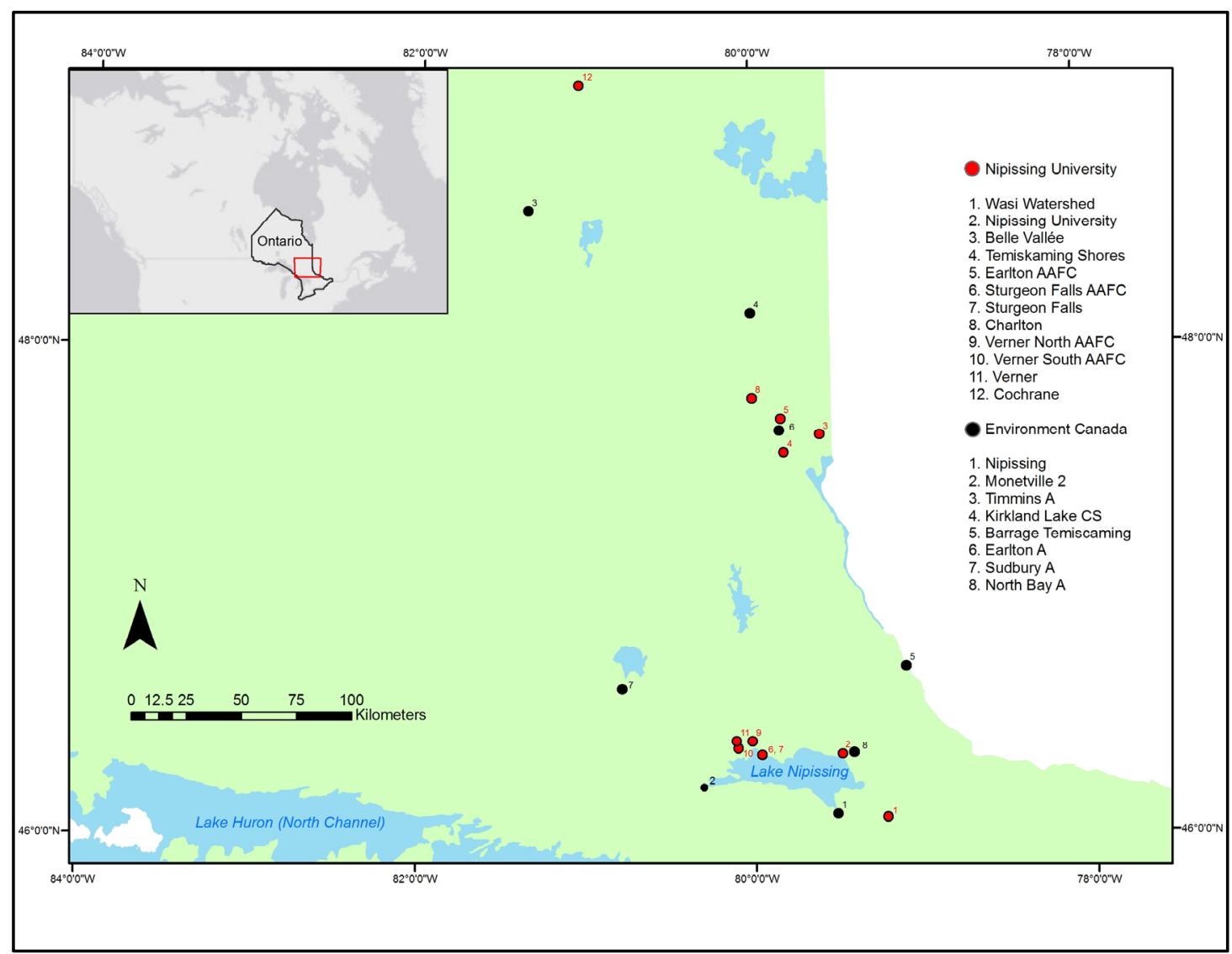

Figure 2. Location of current weather stations maintained by Nipissing University (NU) and by Environment Canada. NU stations numbered 1, 3, 4, 7, 8, 11, and 12 are currently fully integrated into GeoVisage.

\subsection{Real-Time Data Acquisition and Display}

GeoVisage features a real-time data tool that displays graphs of current sensor data from several weather stations. With the Weather Station Data tool, all the data collected by the weather stations from the earliest collected by Nipissing weather stations (some stations as early as 2009) to near present can be viewed. The real-time data component is the standard interface provided by HOBOlink [23], part of the HOBO service. The weather stations use HOBO U30 or RX3000 data loggers (Onset ${ }^{\circledR}$, Bourne, MA, USA) to acquire and wirelessly transmit data at regular five-minute intervals. Both atmospheric and soil properties are measured, with most stations recording gust speed, wind speed, leaf wetness, soil moisture, photosynthetically active radiation (PAR), soil temperature, air pressure, air temperature, rainfall, relative humidity, dew point, and solar radiation.

\subsection{Weather Station Data Visualization}

The real-time data offer a quick view of recent conditions, but lacks the exploratory features needed for more detailed or in-depth analysis. Consequently, GeoVisage provides other features to allow properties from different weather stations or time periods to be visualized and compared. The Weather Station Data Visualization tool offers a much larger selection of features than the real-time data, but is updated less frequently. The tool has interactive time selectors that allow different properties to be compared and assessed across different weather stations and time periods. Basic statistics are also provided in a separate table below the plots. An example time series comparing two stations and two properties is shown in Figure 3. 


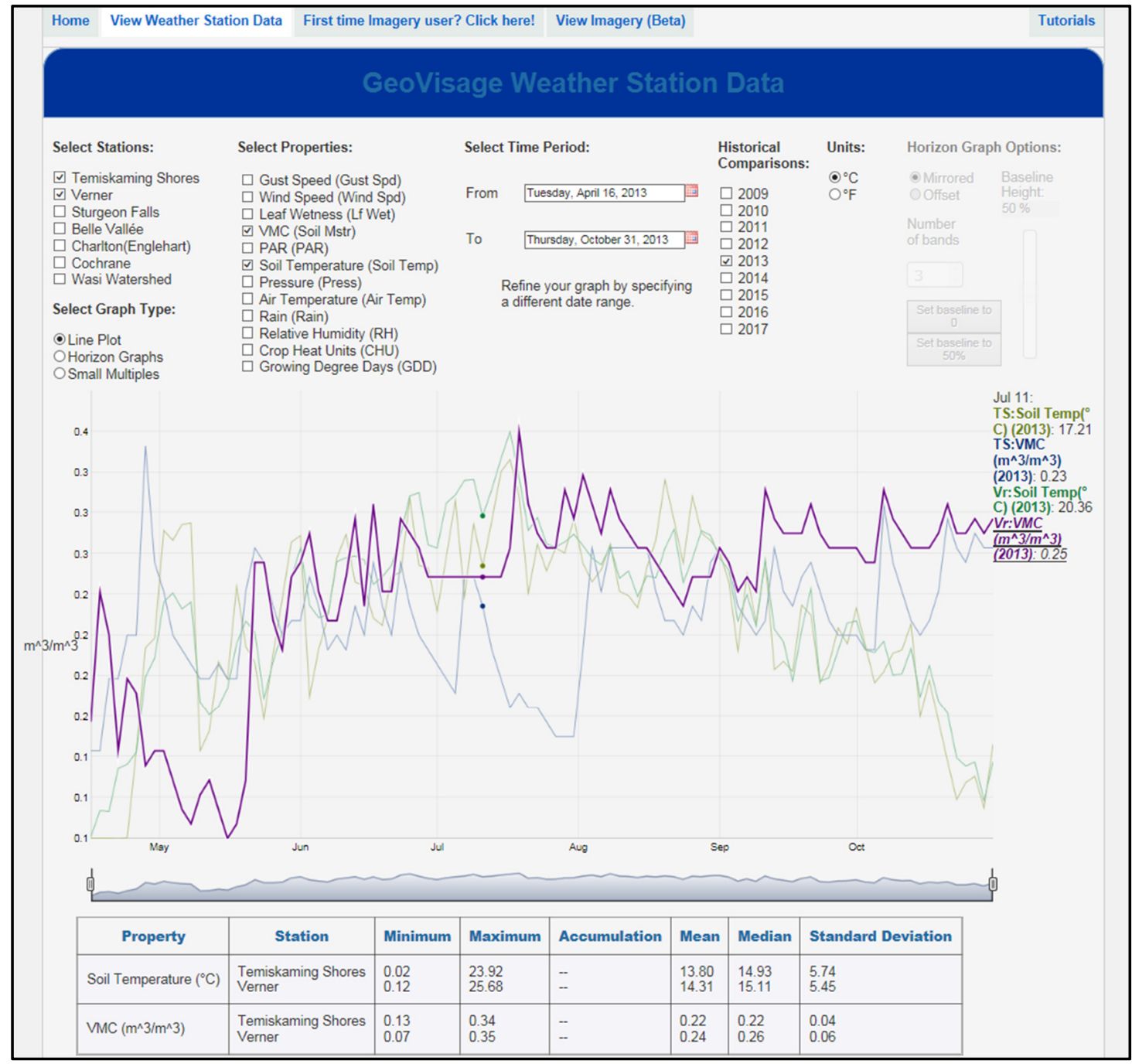

Figure 3. Interface for weather station data. Time series for two environmental properties (soil temperature and volumetric moisture content), comparing two sites (Verner and the more northern Temiskaming Shores region) over a growing season. The time selector below the line plot allows time zooming. Hovering over a time series displays the sensor readings for a specific time and date. The statistics panel is located below the selector.

Visual analytics capabilities, currently in testing with limited availability, have recently been added as a research tool and to facilitate community-based participatory research. Visual analytics features include small multiples and horizon plots for displaying a large amount of time series data on a limited screen space and more advanced time-based correlation and multi-resolution visualizations.

\subsection{Imagery}

Additional features of the GeoVisage resource include an imagery application, based on the Java-based NASA World Wind GIS framework, to display remote sensing images, soil maps, yield maps, and field imagery captured with an unmanned aerial system (UAS, or "drone" technology). GeoVisage employs various types of imagery, such as remote sensing images, soil maps, yield maps, normalized difference vegetation index (NDVI) images (Figure 4), and field imagery captured with either of the two UAS deployed by the university (Figure 5). 


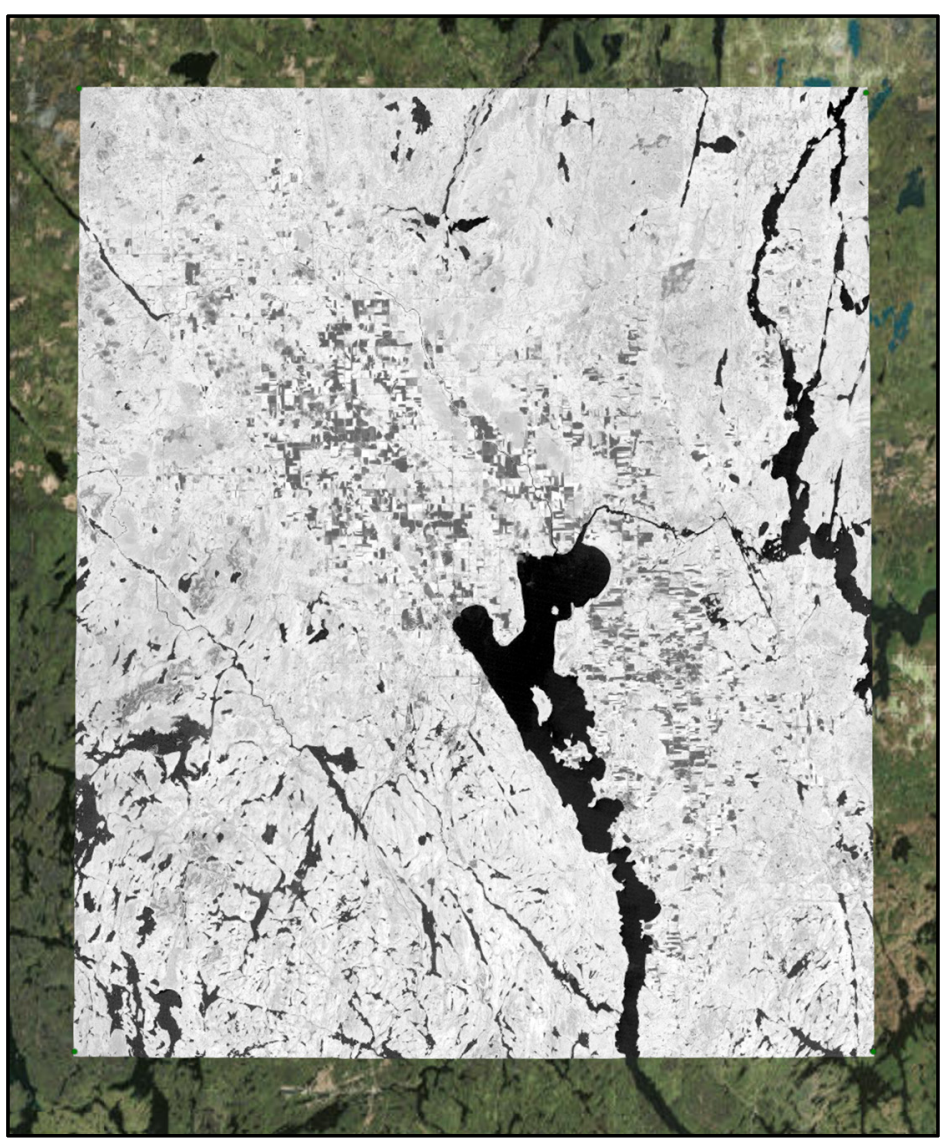

Figure 4. One of many current grey-scale Normalized Difference Vegetation Index (NDVI) images of Temiskaming Shores shown over the World Wind standard image globe (in colour). Bright tones are indicative of high biomass, or healthy crops, whereas dark tones indicate low biomass or no vegetative cover (e.g., lakes and rivers appearing as black).

The remotely sensed imagery includes both UAS and satellite based sensor data. Since the UAS imagery is collected close to the surface (e.g., $\sim 90 \mathrm{~m}$ ) the spatial resolution is extremely high, in the order of a few centimeters per pixel. However, UAS imagery is typically based on hundreds of individual photos that are stitched together using specialized software. Although these images are of high spatial resolution, they cover relatively small areas, often just one field, and require considerable time to collect in the field and process in the lab. In contrast, most of the historical satellite imagery are collected from LandSat sensors which have a $30 \mathrm{~m}$ pixel resolution, or if pansharpened, $15 \mathrm{~m}$. However, these images are collected regularly, every 16 days, and cover an immense area of 185 by $185 \mathrm{~km}$ (i.e., hundreds of fields). 


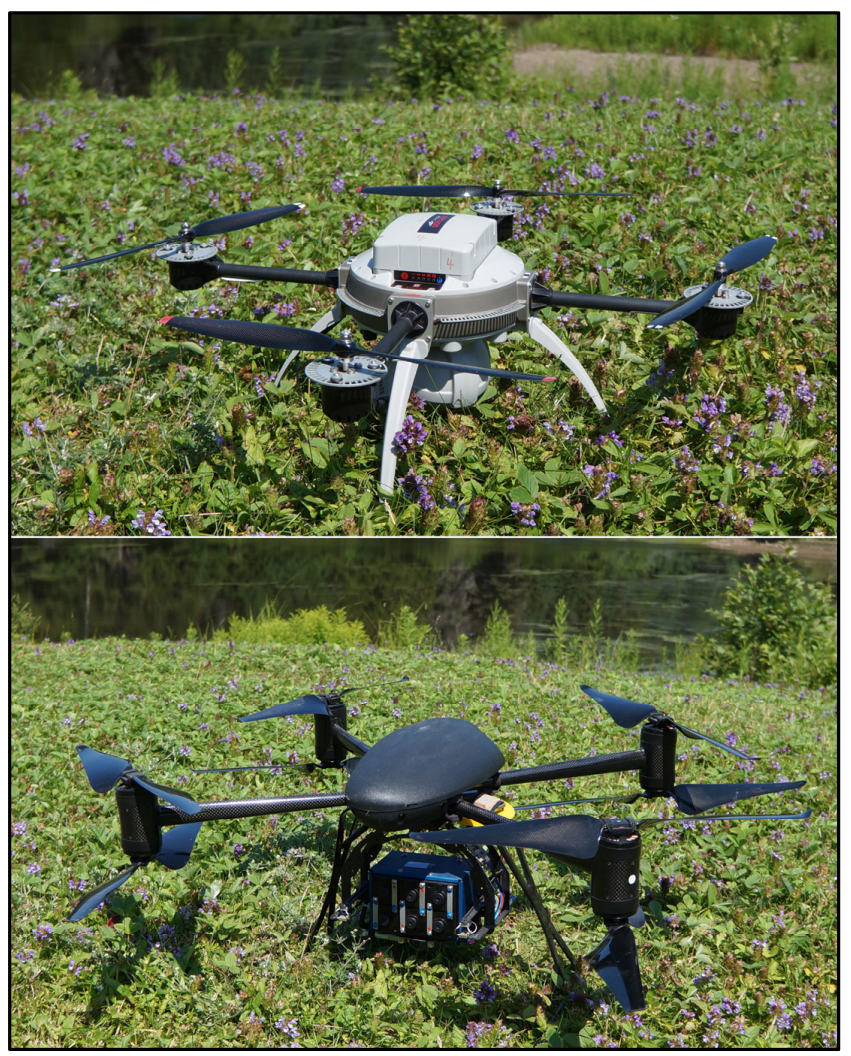

Figure 5. Two unmanned arial system (UAS) quadrocopters deployed by Nipissing University researchers for agricultural monitoring. The Aeryon Scout (Aeryon Labs Inc., Waterloo, ON, Canada) carries (top photo) an infrared ADC lite camera (Tetracam, Chatsworth, CA, USA), whereas the Dragan Flyer X-8 (Draganfly Innovations Inc., Saskatoon, SK, Canada) carries a Mini-MCA camera (Tetracam, Chatsworth, CA, USA).

Measurement tools, provided with the World Wind framework and customized for the application, are provided to facilitate quantitative assessment. An example of imagery overlaid onto terrain as a semi-transparent layer, as well as a field measurement, is shown in Figure 6.

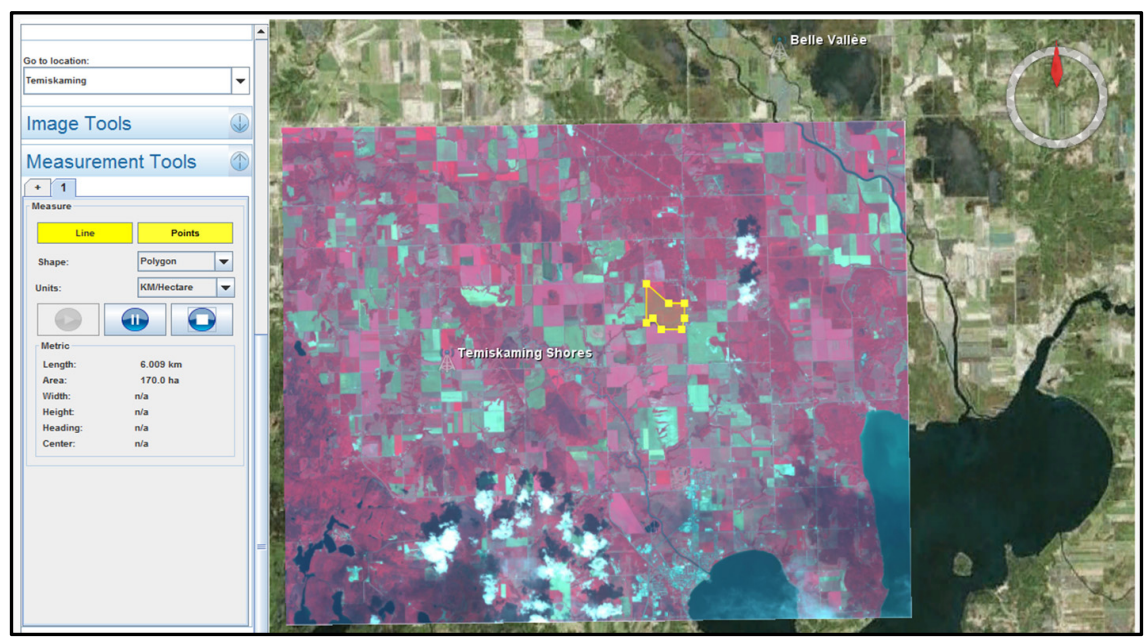

Figure 6. Example imagery overlaid atop terrain provided by the NASA World Wind framework. Tools for the imaging interface are shown at the left. The transparency tool, shown here, allows blending of several images and the underlying terrain. 


\subsection{Geo-Referenced Digital Photographs}

GeoVisage allows producers to upload images of their crops, pests, etc., to facilitate information sharing. Users also have the capability to display digital photos to better identify crop conditions and to alert the community of possible pest infestations. These photographs are geo-referenced to a specific location or to a general region, and are then made available to all GeoVisage users. The feature directly supports the community-based participatory research and "citizen science" aspects of the GeoVisage initiative. An example of this feature is shown in Figure 7.

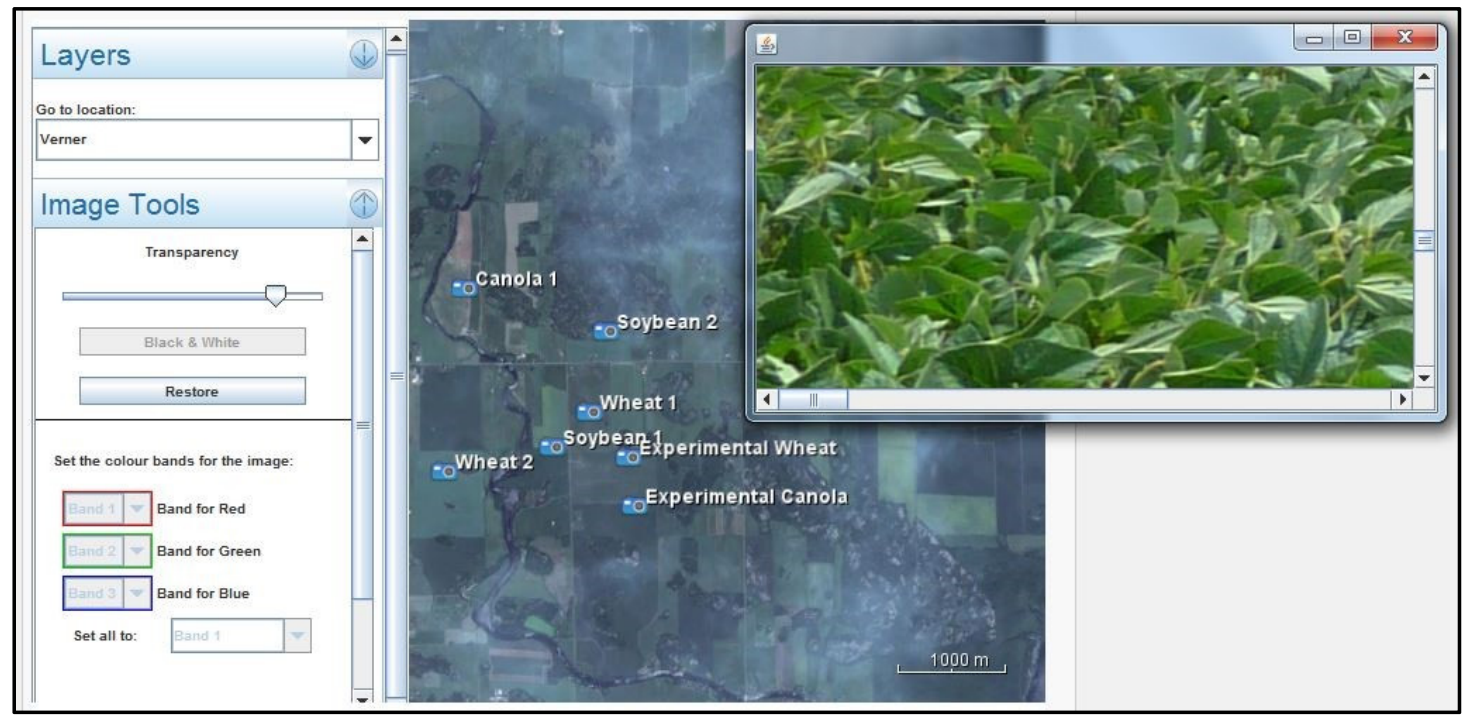

Figure 7. Example of the digital photo-sharing feature. The soybean image is geo-referenced to the "Soybean 2" label on the map.

\subsection{The Importance of Human Computer Interaction}

To encourage adoption by agricultural producers, ease-of-use and intuitiveness were primary considerations in designing the GeoVisage system interface [24]. For instance, the NASA World Wind visualization framework [25] provides producers with the usual zooming, panning, and navigation tools to quickly identify and focus on specific locations, such as their own farms, and is based on standard paradigms characteristic of many GIS products and services. In another example, producers are provided with a variety of colour-maps for displaying time series data to enhance exploratory capabilities, and to take into account users' preferences. Intuitive location, viewing, basic image processing, and measuring tools are also provided. The "broad" (i.e., complex, or "busy") interface paradigm was adopted so that producers have access to a wide variety of tools simultaneously. Because of the importance of training to the adoption of technology tools [11], instructional videos and tutorials (Figure 8) are also available through the system interface.

Finally, but very importantly, major benchmarks in the development of the interface were discussed and assessed with the producers for whom GeoVisage was designed. In the design and development of the system, groups of producers have visited with developers for training, and to provide valuable feedback on the intuitiveness of using various features. The developers also attended farm shows, association crop tours, and other events to communicate with a wider audience of users (see Figure 9). 


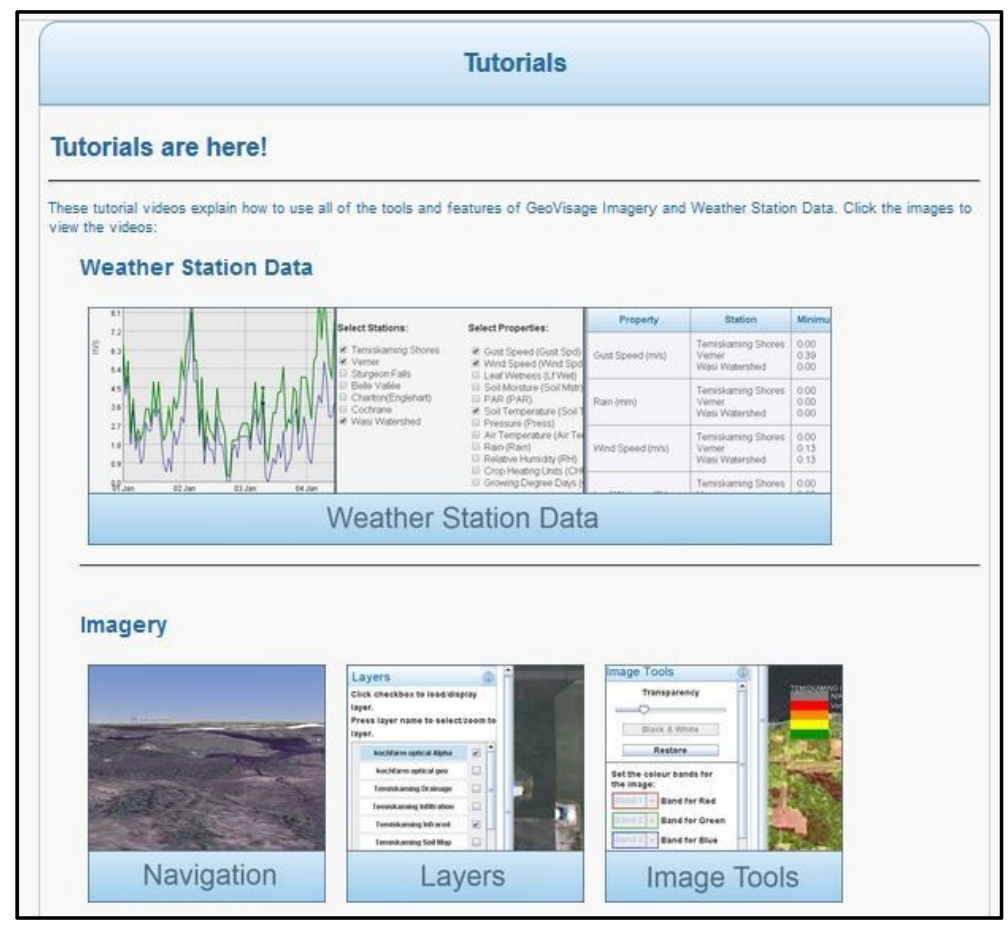

Figure 8. GeoVisage online video tutorials screen-capture.

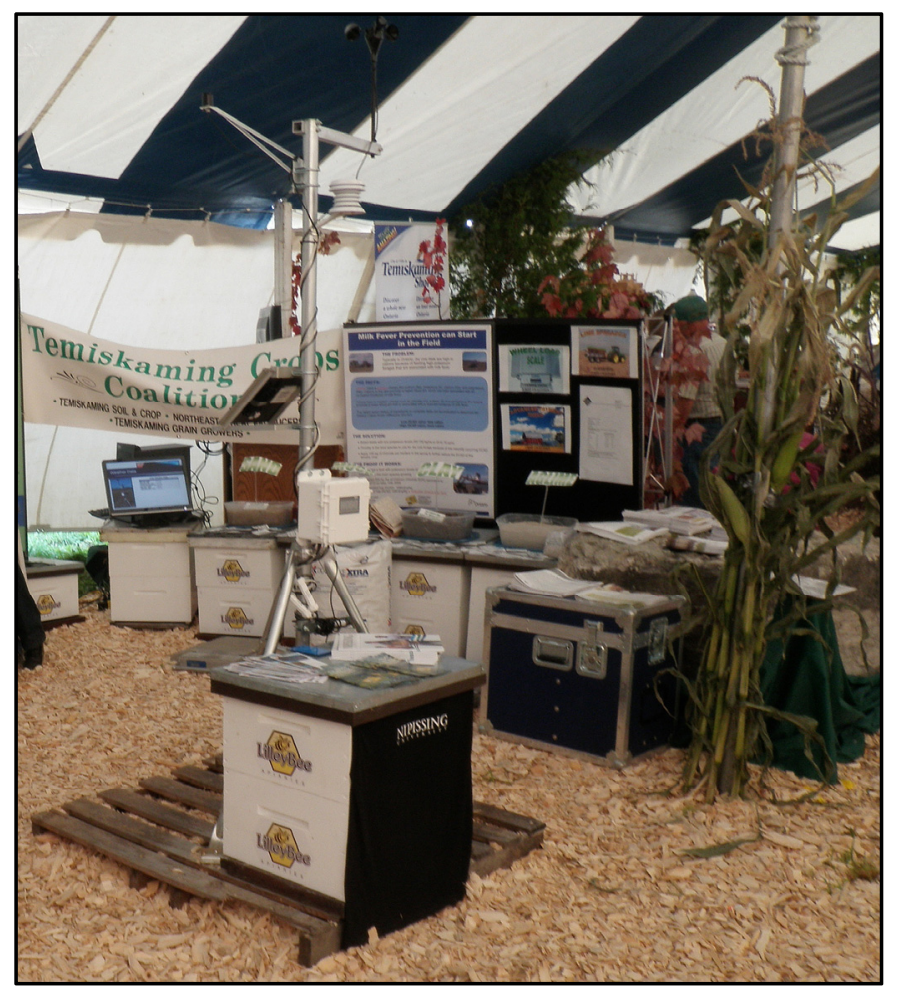

Figure 9. Nipissing weather station as part of the Ontario Soil and Crop Improvement Association/Temiskaming Crops Coalition booth at the 2009 International Plowing Match. The event was held for the first time in Earlton with an estimated 75,000 visitors over 5 days. 


\subsection{Precision Agriculture and Spatial Decision Support Tools}

Precision agriculture may be loosely defined as "The application of geospatial techniques and sensors (e.g., geographic information systems, remote sensing, GPS) to identify variations in the field and to deal with them using alternative strategies" [26]. Although there are many tools for supporting precision agriculture, web services for spatial decision support in particular are growing in popularity because spatial information is easily understood, and because of the importance of sharing agricultural and environmental information. Remote sensing imagery, including images captured by UAS and satellite-based sensors, is an integral component of this new web-based paradigm, characterized by a growing number of research contributions. For instance, CropScape, an initiative of the National Agricultural Statistics Service in the United States [27], is an interactive geospatial web-based system for disseminating, querying, visualizing, and analyzing crop and land cover classifications obtained from remote sensing data. Since it became available as a website in 2011, CropScape has been visited by over 81,000 users (reported as of 2013) [28]. In another example, a web service has been designed for exploiting the availability of global navigation satellite system reflectometry (GNSS-R) signals for assessing soil moisture [29]. Agricultural monitoring is also facilitated by open geospatial web services that integrate heterogeneous information from multiple wireless and wired sensor networks [30].

As mentioned above, GeoVisage provides visualization services, which are key components in enhancing agricultural decision support. GeoVisage and other web services that support data from GPS-based farming vehicles and remote sensing technologies need to visualize a large amount of data that, because of its volume, is difficult to interpret. Visualization is the first part of an extensive data mining process for enhancing interpretation and understanding [31]. Examples of this synergy include a recent study which described a prototype system that supports agricultural decision-making that is enhanced through cartographic visualizations and which integrate current local environmental and agro-monitoring data with a GIS system [32], as well as a web-based system targeted to policymakers and other stakeholders with the goal of assessing the consequences of crop changes on multiple ecosystems [33].

In addition to the technical aspects of web-based tools for agricultural decision support, it is important to understand whether, how, and to what degree these technologies have been adopted by producers [26]. The current study analyzes the factors involved in adoption of GeoVisage through interviews with local producers in two northeastern Ontario agricultural areas: Temiskaming Shores and Verner.

\section{Methods}

The use of interviews and case studies to investigate the adoption of precision agriculture has been successful in pinpointing specific technological needs (e.g., yield monitoring and mapping services) [34]. The current study extends this approach to an investigation of the adoption of the web-based dissemination of location-specific weather data and imagery, and is therefore relevant to other researchers developing web-based precision farming and analytics tools.

With a view to better understanding how northeastern Ontario farmers were using the GeoVisage online resource and weather station data, a multi-site qualitative case study was conducted in 2014-2016. Following the approval by the Nipissing University Research Ethics Board, the study involved site visits to two farms in the Temiskaming Shores area in summer 2014, and site visits to three farms in the Verner area in spring 2016 (see Table 1). 
Table 1. Participating farm details.

\begin{tabular}{cccc}
\hline Farmer(s) (Pseudonyms) & Farm Type & Farm Acreage/Size & Weather Station Access \\
\hline Aidan & Dairy + Cash Crops & $\begin{array}{c}84 \text { head milking (tie-stall } \\
\text { with milkers and } \\
\text { pipeline); } 1500 \text { acres }\end{array}$ & $\begin{array}{c}3 \text { weather stations used } \\
\text { (Belle Vallee, Charlton, } \\
\text { Temiskaming Shores } \\
\text { (located on his farm) })\end{array}$ \\
\hline Ben & Sheep + Cash Crops & 250 sheep; 1235 acres & $\begin{array}{c}3 \text { weather stations used } \\
\text { (Belle Vallee, Charlton, } \\
\text { Temiskaming Shores) }\end{array}$ \\
\hline Carl, Callie, Chris & Dairy + Cash Crops & $\begin{array}{c}80 \text { head milking (two } \\
\text { fully automated milking } \\
\text { stations); } 1000 \text { acres }\end{array}$ & $\begin{array}{c}\text { 2 weather stations used } \\
\text { (Verner (located on their } \\
\text { farm), Sturgeon Falls) }\end{array}$ \\
\hline Dean & Fruits/Vegetables + Cash Crops & $\begin{array}{c}\text { public berry/vegetable } \\
\text { picking, rides; } 650 \text { acres }\end{array}$ & $\begin{array}{c}2 \text { weather stations used } \\
\text { (Verner, Sturgeon Falls } \\
\text { (located on his farm) }\end{array}$ \\
\hline Evan & Dairy + Cash Crops & $\begin{array}{c}80 \text { head milking (tie-stall } \\
\text { with milkers and } \\
\text { pipeline); } 1250 \text { acres }\end{array}$ & $\begin{array}{c}\text { 2 weather stations used } \\
\text { (Verner, Sturgeon Falls) }\end{array}$ \\
\hline
\end{tabular}

Three of the farms involved in the study were dairy operations with approximately 80 head of cattle, two of which used traditional tie-stall milking machine technology, and the third featuring an advanced system with two fully automated milking stations. A fourth farm involved a flock of 250 sheep and was primarily focused on the growing and selling of a variety of cash crops. The fifth site represented a popular, family-run public access farm featuring seasonal berry picking, vegetables, wagon rides, gift shop, and a small eatery. Three of the five farms had agreed to host a weather station on their property; all five farms were provided access to weather station data via GeoVisage.

Interviews were conducted with four individual farmers, and in the fifth case a group interview was conducted with a farmer and his parents, all three of whom were significantly involved in the home farm history and daily operation. Interviews were then transcribed verbatim, followed by member checking, during which stage all participants were able to review transcripts and offer insights into minor corrections/clarifications. The seven farmers were each given pseudonyms (Aidan, Ben, Carl/Callie/Chris, Dean, Evan) to provide participant confidentiality.

The interview questions were semi-structured (i.e., open-ended in nature) and designed according to case study standards [35,36]. Participants were thereby encouraged to communicate their individual perceptions relating to their adoption of the GeoVisage resource and features (see Appendix A). Interviews were transcribed and checked for accuracy, and were also returned to participants for "member checking," allowing them to ensure accuracy of content and to suggest any requested revisions.

Transcripts were loaded into a qualitative software program known as Atlas.ti (Scientific Software Development $\mathrm{GmbH}$, Berlin, Germany), which is a computer-assisted qualitative data analysis (CAQDAS) software package for analyzing text, audio, and video-based research data [37]. For this case study, the researchers employed Atlas.ti because it allowed for the organization of large amounts of text-based interview data; because it allowed the researchers to manually define, apply, merge, and modify thematic codes based on the transcript data; and because it allowed the researchers to establish and export to word processing software the emergent main themes and related quotations to expedite the writing process. The researchers employed a common thematic analysis method that involved familiarization with data, generating initial codes, searching for emergent themes among codes, reviewing themes, defining and naming themes, and producing the final paper.

\section{Results}

From the interview data, fifteen separate codes were identified and subsequently grouped into three broad themes for discussion purposes. In what follows, we shall examine the perceptions of participating farmers relating to commonly used weather station measures, other uses of GeoVisage 
website tools/data, and future recommendations for the decision support tool. Note that some of the GeoVisage features elaborated upon in Section 2 above are not represented in the qualitative results and discussion sections, as the participants, when asked about their own experiences with, and perceptions of, the GeoVisage tool, did not mention these particular features.

\subsection{Commonly Used Weather Station Measures}

Farmers participating in the study indicated the common use of four key types of weather station measures: air temperature; rainfall, leaf wetness, and relative humidity; soil temperature; and wind speed and direction. Relevant excerpts from the interview conversations are presented to provide further insight into how and why these measures are often used in everyday farming decisions.

Not surprisingly, there are essentially three aspects of general weather patterns that are of interest to farmers: what is happening "today" with the weather (present); what has happened historically in terms of the archived comparison data (past); and, perhaps most importantly, what is being predicted in terms of "tomorrow" and the remainder of a given week or month (future). In speaking with participants in this study, it became clear that understanding all three of the above chronological aspects of weather station and website data is vitally important for their everyday work and decision-making processes.

All of the participants check weather forecasts on at least a daily basis, if not several times per day depending on what season they are in, and on what decisions have to be made concerning crops. A number of popular weather forecast websites were reported as being used for this purpose such as AccuWeather, the Weather Network, and Environment Canada's Canadian Weather Radar site.

\subsubsection{Air Temperature}

Ben, one of two brothers who have taken over the operation of the family dairy farm business, indicated that he has commonly used GeoVisage for checking both temperature and rainfall measures.

Ben: So, through the growing season we would be on that site, I would say every day. We would definitely want to know the amount of heat that's coming, like what our highs and lows were for the day, and how much moisture we actually did capture ... I am checking the amount of rainfall and temperatures through the day, and we make decisions on impending weather conditions - whether or not to plant, whether or not to spray, whether to work all night if there's an impending week of rain coming. These are more precise measurements that we would rely on, as opposed to just checking Environment Canada.

Dean, who maintains the publically accessible berry-picking farm, discusses how air temperature is one of his most important considerations in order to avoid frost damage to the berries after planting.

Dean: We have alarms, but if there was frost on the strawberries, and you didn't get at them at night to put the sprinklers on, then they get damaged, so you assess the damage, and might have to cut back on your sales that day ... The water's warmer than the air, so just the effect of adding the warmer water does bring up the temperature, but if it forms ice, the creation of ice being formed actually creates heat. It's weird. So, as long as you don't let that ice become dry on the flowers-on the blossoms, then they'll be saved ... So, we keep it wet constantly. We have to make sure we come back to the same field within $15 \mathrm{~min}$. So, we rotate fields ... It's all night, yes, driving around, walking around-we have to shut off valves, open valves, check a lot of things ... They're all set up around the fields, but the pump can only handle so much at a time, so it's a matter of switching from field to field.

An additional temperature sensor was added to the weather station on Dean's farm to measure air temperature above the height of the strawberries. Dean had also described the frost as a river of cold air moving over the canopy, and that a temperature sensor at the height of the berries is a better estimate of frost risk. 
A dairy farmer located near Dean's farm noted the importance of knowing when to expect frost for other types of crops:

Evan: Frost is still fairly important after we plant, to see how cold it is - this year we had a scare after the Canola was up. We had a couple of nights that we had frost, and Canola can be susceptible if it freezes too hard, and soybeans the same thing... At certain times of the year, yes, we check carefully. Come later on in the fall, it doesn't quite matter as much.

Clearly, with so much riding on decisions relating to frost, freezing, and crop failure, weather station data pertaining to air temperature ranks among the most significant use of weather station data.

\subsubsection{Rainfall, Leaf Wetness, and Relative Humidity}

Related closely to air temperature in terms of features of the weather station data and the GeoVisage website that were reported as being particularly useful for farmers was rainfall, or precipitation measurement. Dean contrasts traditional methods of tracking rainfall with more modern measures:

Dean: All farmers are interested in weather and what's happening at their own farm because even before the weather stations were built, most farmers actually had a rain gauge on their farm, which we did ourselves too. But this one, we don't have to do anything-it's done for us ... It's very useful to know how much rain has fallen in the last $24 \mathrm{~h}$-for decisions if we should irrigate or not, for example ... The one measure I look at the most, yes, is rainfall.

Evan, located within the same region in Ontario, explained how rainfall affects field conditions:

Evan: Everybody used to have rain gauges on their farms to measure what you would get. Now I think a lot of people look this up online. It also gives you an idea of how much moisture is in the ground ... If you got two inches of rain, you know you won't be going into the field for a couple of days ... The long range doesn't really interest me that much, but the prior 2-3 days, that's useful information.

Chris and his parents, Carl and Callie, who all take part in their family dairy business, expressed the importance of consulting weather forecast websites and radar data in terms of their decision-making:

Chris: For forecasting, it's sort of halfway between the Weather Network and Environment Canada. Weather Network's too optimistic. Environment Canada's too pessimistic. It's usually about halfway in between.

Callie: The forecasting is really interesting because if you can see the radar, you can make the judgment call as to what's going to happen... We always get the radar out.

Aidan, a dairy farmer (along with his brother) who had a Nipissing University weather station located on his own farm, noted that he regularly checked the website regarding precipitation measures:

Aidan: If it rained, I would definitely check it the next day, but at least once a week-just to see how much rain we got. So, you know, if I woke up in the morning and there had been any precipitation at all, I would click on it just to see what amounts we got. Because everyone has a plastic range gauge outside of their house, but how accurate are they, compared, you know, to a scientific rain weather station? It could vary greatly.

Ben reported regularly checking the data from the weather station located on nearby Aidan's farm, as well as data from two other local weather stations that were all made available through the online GeoVisage resource: "Because there is quite a variance-in May we had a two-and-a-half inch rain capture here ... It was good to check Belle Vallee and Charlton as well-those three, and to see, 
you know, that there is a variance in the amount of moisture." Precipitation measurements would often vary throughout the region, and hence multiple data points, taken together, were viewed as providing a more accurate picture of overall rainfall patterns.

Closely related to rainfall precipitation were the separate measures of leaf wetness and relative humidity. Although neither of these factors were discussed at length by any of the farmer participants, a few comments were shared in this area. For example, Chris noted that both leaf wetness and relative humidity are important factors when deciding when to cut and bail hay crops. Furthermore, Aidan explained how both of these measures also affect decisions surrounding the harvesting of wheat crops:

Aidan: When we get heavy dews during the day, in the morning, there is a critical time for wheat, and its right at heading time-so, when the wheat elongates out of the stem, that's what they call a critical time for disease prevention ... If you think it's dry out, you don't really know the leaf wetness of the crop, and you don't know the humidity. So, two critical things are the amount of moisture of the leaf, as well as the humidity in the air, because these both breed disease.

Another commonly referenced weather station measure, regardless of the type of farm, was that of soil temperature.

\subsubsection{Soil Temperature}

The temperature of the soil can directly affect the survival of newly planted seeds, as well as overall sustainability depending on the nature of the crop and the soil bed in which it is planted. Aidan contrasted traditional and more current soybean planting decisions in light of the available data.

Aidan: When planting beans, it's more critical that the soil temperature be high enough for the beans. They say that when you plant beans in a cold ground it actually shocks the beans, and it will delay the growth. That has really been a useful tool ... We used to go out and plant when the ground was dry-we could get on the field without getting stuck. We planted more by the calendar, like it was the first of May, so you would go out and plant. Now we can plant by the temperature of the soil-if the soil is actually ready. It might be dry, but if it's been a few cold nights and the day temperature hasn't warmed the soil up, then, you know, we will hold off.

Evan echoed this general rule of thumb in terms of planting temperature, noting that "for cereals it's not as important, but for soybeans, they want the temperature to be at least 10 degrees-they recommend ten degrees for the first $24 \mathrm{~h}$." Aidan also mentioned the snow insulation factor, which can affect certain crops and pests:

Aidan: It is surprising, the soil temperature, depending on the amount of snow we get-because you don't realize the insulating factor of snow. The soil temperature will only be minus two or three degrees, so with these new pesticides, this new pest we have, the Swede midge in the Canola crops-although it was minus forty, they assumed it was going to kill the bugs in the ground. But we had such a large amount of snow it actually worked as an insulator, and so the ground didn't get that cold ... We got a spring thaw, so that created a sheet of ice, and it cut the oxygen off ... but it recovered from it. So, with tools like that you would go on and see the soil temperature, you know-is it below freezing still, or is the ground starting to warm up?

We have thus far looked at measures of air temperature, precipitation/humidity, and soil temperature. A fourth weather station data measure commonly referred to by farmer participants was that of wind. 


\subsubsection{Wind Speed and Direction}

Wind speed and direction are two factors that affect several aspects of modern farming. When asked if he used pesticide sprays on his fruit and vegetable farm, Dean noted that "pesticide spray is needed, yes, especially for the cash crops. It's good to check and see what the wind speed is-if there's too much gusting ... It depends on what you're applying-some products are at the very most $15 \mathrm{~km}$ per hour, and some have more chance of drifting than others."

Aidan further explained that "you could waste a lot of product, or get yourself in a bit of trouble, if the wind speeds are too high ... Like just the drift-you don't realize, if you're in a sheltered area, just how windy it could be out there." Similarly, Carl maintained the same rule-of-thumb wind speed threshold: "Yes, I use $15 \mathrm{~km}$ per hour. If it's over that, I kind of hold off ... If you're growing cereals and your neighbours have Canola or something on another side of a ditch-if the wind's blowing the wrong way, you can actually do damage to other fields."

The frequency with which a farmer checks different weather station data is also of interest. With soil temperature, for example, Evan explained that hourly or daily checking often suffices; whereas with wind speed, a farmer may more often wish to be checking this measure every 15 min given how volatile the weather patterns can be in this regard. Carl spoke about the importance of relying on the weather station data, rather than just on sometimes inaccurate visual or tactile impressions:

Carl: So, there's a limit really, of $15 \mathrm{~km}$ per hour-beyond that, yes, it's just too windy. So, you're standing outside and a gust of wind blows by, and you think it's too windy-so you go check. But it's only reading $12 \mathrm{~km} / \mathrm{h}$. Maybe that gust was $20 \mathrm{~km} / \mathrm{h}$, so it's actually okay, it's fine, it should be all right, and so I'll go and spray. But without this reading, I might have said, 'Forget about it for today.' ... That's why wind direction is important, especially if I'm spraying in a field next to another person's house. I don't want to spray them if I can help it.

\subsection{GeoVisage Imagery Data}

During the course of the five farm-based interviews, participants discussed the GeoVisage imagery data and tools that were also being developed for, and accessible through, the GeoVisage website. Using World Wind capabilities, a measurement tool was developed which allowed users to measure acreage. Further, UAS (i.e., Aeryon Scout, DraganFlyer X8) with cameras were used to capture rich crop imagery of several participating farms.

The UAS technology was demonstrated during an annual agricultural event in the Temiskaming Shores area during the weekend of the first interviews in 2014. Clearly, there was already much interest being generated around this technology and the potential utility of the high-resolution imagery being produced. GeoVisage offered both a land measurement tool and the UAS imagery of participating farms. Farmers referenced both of these features during interviews, some having used them more than others. However, the post-processing of UAS imagery and integration into farm-scale technology remains a constraining factor in widespread adoption by small-scale producers [38].

\subsubsection{Acreage Measurement}

Aidan described two critical uses of such a measurement tool in farming:

Aidan: We are now in the year of high rent, you know. We are up into the \$160-per-acre-per-year range for Temiskaming, which is unheard of. So, if you can scientifically measure out the acres that you are cropping, and then only pay for those acres. If the farmer you are renting it from claims it's a 160-acre farm, but really it's only a 140 workable acres, that's 20 extra acres that's not being used. But also for crop insurance. Agricorp wants to know exactly how many acres you are cropping. Markers on drills and acre meters on drills are only so accurate. 
Accurately calculating crop acreage also relates to projected crop yield, and hence has sale implications:

Dean: I thought it might be a tool in the future to say, you know, "Close to how many tons of soybeans can you pull out of that certain field?" And so that could help you gauge how to sell it-if you know you have so many tons, you can sell them in advance because you don't want to sell too much. And if you sell on the stock market you owe the stock market regardless of your crop yield-you have to fill in what you agreed to sell.

Two other significant areas of land use decision making that relate to acreage measurement are the ability to plan for adequate tile drainage, and the annual purchase and application of crop fertilizers.

\subsubsection{Tile Drainage and Fertilization}

Another aspect of remotely sensed imagery relates to irrigation and tile drainage decisions. Farmers can view their land using various filters within GeoVisage Imagery, and low/wet spots can be identified. For instance, particularly wet fields may not be appropriate for winter wheat because of the episodes of freezing in this region.

Aidan: People think that they are on flat ground ... If you know the lay of your land, when you are out there seeding or combining-especially combining-if you have a low spot or a high spot on the farm and you didn't realize it was that much higher or lower, and you start to realize that's why the crop's not growing there very well, or that's why it gets flooded out.

Within the same township, Ben, who specializes in cash cropping using high tech equipment, agrees with the importance of remotely sensed imagery in potentially influencing decisions around drainage and yield.

Ben: One of the things might be capturing moisture levels remotely. Whenever we have a combine yield monitor running and we see variability in the field, $80 \%$ of the time it will be too much moisture in the soil. This will probably be the biggest benefit financially to the farmer. So, whether that means more tile drainage needed, or that something is wrong with the existing tile, you have got to answer those questions. We had a wet spring and farmers went out and compacted their soil. You will see lot of yellow fields, where farmers were impatient and went out and spread manure and compacted the soil with their machines ... So, if you could have those elevations in there, all of those things might aid you in planning efficient water movement.

Not only does imagery provide farmers with watershed and field drainage information, it can also generate imagery that can allow farmers to analyze crop performance relating to fertilization decisions. Dean explained how he had found this aspect to be the most promising for his purposes.

Dean: Well, the first time I used the imagery it was more for prediction. I wanted to see the difference between applying different amounts of fertilizer ... We could see the difference made between the different application rates of fertilizer when we were done harvesting.

Thus far we have discussed how farmers had been using the GeoVisage online resource for weather station data access, land measurement, and remotely sensed imagery information. In the next section we will now turn to future recommendations of the participating farmers regarding the GeoVisage resource. According to our group of northeastern Ontario agriculture producers, how might this tool be improved?

\section{Discussion}

Participants had used the GeoVisage online resource in varying degrees, and for a variety of purposes as detailed above. Three of the five farms involved in the study had allowed weather station 
towers to be constructed on their respective farm properties. Long-term working relationships had clearly been established between the researchers and the participating farms. When asked about feedback and recommendations, interviewees were open, positive, and respectful, offering a number of insightful suggestions dealing with new or adapted GeoVisage features and ongoing support.

\subsection{Internet Access and Communication}

One of the difficult issues surrounding the development of GeoVisage was that, since a variety of organizations had been funding the initiative over time, there would sometimes be periods wherein weather station maintenance and/or online resource development would be temporarily put on hold pending new funding and/or changes in development and support staff. This situation occasionally led to what was perceived as a lack of communication between the farms and the university.

Because of the computational demands of imaging applications in general, and the bandwidth requirements of web-based visualizations in particular, there were also some Internet access and browser issues that limited the ability of some participants to access certain project features and tools. For example, when asked about high-speed Internet access, which is preferred for the proper functioning of certain GeoVisage features, Evan noted "it's a private service provider-they call it high speed but really it's not... So, I mean some days it's great and other days it's not as good, but I think it should be able to handle it."

Some of the issues related to properly accessing GeoVisage had to do with the particular Internet browser being used (e.g., Chrome, Firefox, Internet Explorer, Safari). Due to several technical factors, including the utilization of Java technology in the World Wind framework, some browsers required specific security settings to make GeoVisage imagery features accessible. In response to these various scenarios, the research team created a series of online video tutorials with graduate assistants to help farmers download the required Java updates and to modify security settings in order to access the various tools. Aidan found these browser set-up tutorials, which could be reviewed as needed, to be very helpful: "I was lost until you had her speak through it on the video. Then you can pretty well keep up with her, and then you can pause it, and find out where or what she is talking about, and then just continue on." However, some participants still found the process to be challenging due to the technical requirements of the imagery tool.

Ben indicated during his interview that he would have liked more frequent communication between the university and his farm in terms of the new features being added and improved over time: "as long as we have a contact, I think that's the biggest thing. If somebody was maybe appointed, so when more farmers see it, and they have a go-to person, or even if there was a chat line perhaps?" Evan mentioned the idea of further education around the resource: "I think it would be good to promote it a little bit more to get farmers interested in using it regularly. Maybe even a little course, just to know how to use all of the features."

Overall, however, all five participants clearly thought very highly of the university research team and were excited to be actively taking part in this project over time. What follows are related comments made by participating farmers from within the two different communities involved in the research study.

Aidan: If it's easy to use, that'll be the big thing-everybody will use something that is easy to use ... It's a great tool. Nipissing has sort of stuck with us here in the north, and I appreciate it ... It'll always be new to us-it's all cutting edge information, right? But I know when they come to the farm show they always get a good response at their booth. There is always somebody talking about something, and I just hope that they are getting out of it what we are getting out of it. We don't show it sometimes, but we do appreciate what they are doing, especially for now, and beyond-because farming is only going to get more and more high tech. 
Having built strong working relationships with farmers in these two northeastern Ontario communities over multiple years and involving a number of different project initiatives, the researchers had opportunities for open communication and to acquire useful feedback.

\subsection{Crop Imagery}

Along with his sons, Ben runs a large cash crop farming operation that utilizes very complex, technology-enhanced machinery and processes. Not only does he sell his crops through a local co-operative, he also contracts out to international businesses in terms of planting, monitoring, and harvesting select crops for the international market. Part of this process involves carefully negotiating these contracts and maintaining open communication with his various employers. As he explained during the interview, these companies often require ongoing, documented photographic data of the crop being grown for them. Hence, Ben sees the addition of such a feature in GeoVisage as a useful tool.

Ben: Some of the things I could see fitting in this are crop progress reports to end-users. So, for instance, we have a buckwheat project with Japanese buyers, and they want to be very involved in this project. They like to see imagery, they want field notes from individual producers, and how that specific field is progressing. So, the ability to actually import pics, and to add notes to those pics, to report on the progress-everything from disease pressure to crop conditions- that we could import imagery ourselves, and export that file to these end-buyers so that they can view all of their fields, and all of their sites, because they are dealing with multiple farmers in northeastern Ontario.

What was being recommended here was a potential secure photo/data sharing system that could perhaps incorporate not only digital still photography taken by local farmers and shared with employers through the GeoVisage resource, but also UAS imagery of field growth conditions and crop progress.

\subsection{Mobile Access}

Perhaps the most commonly mentioned item by all participants during the interviews, regarding future recommendations for the online GeoVisage resource, was that of making it more accessible with a user-friendly mobile application version for smartphones. It should be noted GeoVisage was originally developed as a decision-support and research tool, and not primarily as a real-time monitoring system; consequently, mobile utility is somewhat limited. Farmers in the study all used smartphones in their daily work for communication and information purposes, occasionally even checking them during the interview proper regarding incoming calls or messages.

One key use of smartphones in contemporary farming is that of crop rotation and tracking in order to help replenish soil and to avoid crop diseases. Ben explained the nature of his crop rotations.

Ben: To grow crops you need a rotation. Oats, wheat, and barley are a grass plant, susceptible to the same diseases and the same kind of sprays. You need a broad leaf plant, like a soybean, or Canola because they require a different spray, and so you break disease pressure. If you just grow a grass plant year after year, any of those fungus diseases, if they attack one grass plant, they will probably attack again and again. But, if you start rotating a broad leaf canola, soybean, or flax, for example, you would get a mix of weeds and disease, and you could then throw something new at it all the time.

Similarly on the fruit/vegetable farm, crop rotation is a key feature of Dean's annual planting decisions:

Dean: We try to never grow the same thing in the same spot, year after year ... The berries, we'll let them produce for three years, but after that, I won't go into strawberries at the same spot for at least five years ... We don't fumigate any of our crops, so in order to avoid 
a lot of diseases we have to do crop rotation ... Well, you plant something else-every crop has its own specific problems, specific funguses, so by rotating it, you break the cycle and disease doesn't have a chance to build up ... For berries, I'll plant maybe corn afterwards, and then I'll put maybe pumpkins the year after that.

In order to keep careful track of the annual planting decisions, maps are used, both print and digital.

Dean: We have a laminated map in every tractor and all of the fields are numbered. But all of the actual inputs, everything is logged into an app that I have called Field Tracker-Carl's son created it. So, I can touch any year, any field, and I can know all the inputs from start to finish, what was done in that field ... This use to be done on paper, but now it's done on the go. As I'm planting, I'm recording - the date, the seed name, and even the seed variety, the machine setting, and what fertilizer I've applied-everything ... It's all cloud-based on the Internet, so I could break my phone, or lose it, and I'll never lose this data.

Clearly the farmers in this group are all using their smartphones regularly for activities such as emailing, crop tracking, weather forecast checking, price comparison and purchasing, digital photographs/video of crop growth, and general communication with their business partners, family, and other individuals/companies, etc. Developing a GeoVisage app that would work well on a number of different mainstream devices (e.g., iPhone, Windows phones, Android, Blackberry) would no doubt incentivize farmers to use it even more frequently. That being said, it was pointed out by several participants that certain features on the GeoVisage online resource (e.g., comparative weather data with graphs or charts) are easier to read and interpret on a large computer monitor, rather than viewing the data on a smartphone or even a tablet or iPad.

According to Dean, when it comes to daily email activity, he probably does " $60 \%$ out of the pocket (via smartphone) throughout the day, compared to maybe $40 \%$ at the desktop" back at the farm office. Chris shared similar thoughts about the benefits of mobile access: "as soon as it's desktop-based, it becomes less helpful, because if you're spraying, you're not at home in an office, necessarily. You're at the site. You've decided what spray you're going to use, and then to decide if it's time to spray-you're not going to drive home to find out."

Finally, Evan made the point that it would be nice to not only have a GeoVisage mobile app for smartphone, but that it also would be convenient to include in such an app a direct link to, or an embedded measure from, one or more weather forecasting networks which farmers already check regularly throughout the day. He noted specifically that "if there was a place to go to the Weather Network right there, that would also be great. I know that the Dairy Farmers of Ontario just added this last year to their website-you can click onto the Weather Network... It actually locates where you are, using GPS, so you just click on it and it gives you exactly what's going on with the weather there." Four new stations serving the farmers in northeastern Ontario provide access via direct link with a mobile app. The data are not yet integrated into GeoVisage. However, it addresses some of the suggestions from users about increasing accessibility in the field.

\section{Conclusions}

As stated at the beginning of this paper, the main research goal was to gather information about the utility and perceived usefulness of the GeoVisage online resource by participating farmers. As the results have shown, the individuals at all five farms (three dairy, one cash crop, and one fruit/vegetable) took advantage of the online GeoVisage weather station data in different ways and in varying degrees; and some had also taken time to explore the newer GeoVisage imagery tools and video tutorials.

Several recommendations regarding existing and additional features (e.g., secure crop image sharing, mobile app access) were shared within the interviews. Overall, the GeoVisage project was perceived by all participants as representing a very useful set of tools for their complex everyday work. As Dean noted, "they're helpful at the moment for making decisions, and they also have much 
potential for future usage ... All farmers are interested in weather and what's happening at their own farm."

Community-based participatory research endeavours, such as GeoVisage, require engagement with end-users, and such interaction with users is rapidly becoming indispensable for the successful adoption of precision agriculture and agricultural decision support tools. As an example of the community-based participatory aspects of this project wherein feedback from users is vital for continued development, from the results of the interviews of current GeoVisage users presented in this paper, future research and development of GeoVisage will focus on secure imagery interfaces that require less configuration, more support for mobile app visualization and communication, and a greater range of data graphing and visualizations options integrated into the real-time component of the system.

As researchers continue to work closely with northeastern Ontario agricultural producers in further developing this particular type of spatial decision support tool within a positive and participatory framework, they are hopeful that increased adoption and improved effectiveness will characterize this already promising and clearly beneficial resource for agronomists, fruit/vegetable growers, and livestock farmers alike.

In this paper, we have presented empirical evidence that supports McCown's research showing that collaborative decision support system development will lead to the likely adoption and use of the system. More broadly, for other agricultural decision support tool developers, we have found that the regular contact, communication, and feedback demonstrated in this collaborative research initiative are essential to maintain trust and to build lasting relationships, which ultimately contribute to prolonged and meaningful use of the technology and to continued improvements.

Acknowledgments: This research was made possible by a grant provided to D.W., J.M.K. and M.P.W. from the Northern Ontario Heritage Fund Corporation (Project \#920161), and through Natural Sciences and Engineering Research Council of Canada funding to J.M.K. (Grant \#RGPIN-2014-06188) and to M.P.W. (Grant \#386586-2011). We also thank Renata Wachowiak-Smolíková for helpful suggestions and proofreading.

Author Contributions: All four co-authors conceived and designed the study. M.P.W., D.W. and J.M.K. have developed the GeoVisage software over time, and have also established ongoing professional relationships with local farmers in a number of projects. D.H.J. conducted the qualitative research interviews with the participating farmers. D.H.J., M.P.W., D.W. and J.M.K. all contributed to the paper.

Conflicts of Interest: The authors declare no conflict of interest.

\section{Appendix A. Interview Schedule (Questions)}

1. Please explain your involvement with the weather station and GeoVisage online support tool project to date? How and when did you become involved with this project?

2. GeoVisage is accessible through the Internet. Is high-speed Internet adequately available within your local area (home/barn office)? Would most local farmers be able to access Internet?

3. The GeoVisage website has been updated several times over the past few years. To date, could you describe how often, and in what ways, have you used the GeoVisage website as a farmer?

4. Do you have any suggestions regarding the improvement of the existing features, or possibly any suggestions regarding the addition of other features to the GeoVisage website?

5. Overall, in your opinion, how helpful is this website resource for your work as a farmer?

6. The aerial imagery is the newest addition to the website resource. Is this something that you might be interested in becoming involved with? How would this be useful data for your farming?

7. Do you have any further comments, or other questions for the research team at this time? 


\section{References}

1. Aubert, B.A.; Schroeder, A.; Grimaudo, J. IT as enabler of sustainable farming: An empirical analysis of farmers' adoption decision of precision agriculture technology. Decis. Support Syst. 2012, 54, 510-520. [CrossRef]

2. Barr, S.; Sharda, R. Effectiveness of decision support systems: Learning or reliance effects? Decis. Support Syst. 1997, 21, 133-146. [CrossRef]

3. Bochtis, D.D.; Sorensen, C.G.; Green, O. A DSS for planning of soil-sensitive field operations. Decis. Support Syst. 2012, 53, 66-75. [CrossRef]

4. Burgos-Artizzu, X.P.; Ribeiro, A.; Guijarro, M.; Pajares, G. Real-time image processing for crop/weed discrimination in maize fields. Comput. Electron. Agric. 2011, 75, 337-346. [CrossRef]

5. Guillard, V.; Buche, P.; Destercke, S.; Tamani, N.; Croitoru, M.; Menut, L.; Guillaume, C.; Gontard, N. A decision support system to design modified atmosphere packaging for fresh produce based on a bipolar flexible querying approach. Comput. Electron. Agric. 2015, 111, 131-139. [CrossRef]

6. McCown, R.L.; Hochman, Z.; Carberry, P.S. Probing the enigma of decision support system for farmers: Learning from experience and from theory. Agric. Syst. 2002, 74, 1-10. [CrossRef]

7. Nute, D.; Rosenburg, G.; Nath, S.; Verma, B.; Rauscher, H.M.; Twery, M.J.; Grove, M. Goals and goal orientation in decision support systems for ecosystem management. Comput. Electron. Agric. 2000, 27, 355-375. [CrossRef]

8. Walters, D.F.; Smolikova-Wachowiak, R.; Wachowiak, M.; Shrubsole, D.; Malczewski, J. Ontario's Nutrient Calculator: Overview and focus on sensitivity analysis. J. Agric. Sci. 2013, 5, 189-200. [CrossRef]

9. Cerf, M.; Jeuffroy, M.-H.; Prost, L.; Meynard, J.-M. Participatory design of agricultural decision support tools: Taking account of the use situations. Agric. Sustain. Dev. 2012, 32, 899-910. [CrossRef]

10. Rossi, V.; Salinari, F.; Poni, S.; Caffi, T.; Bettati, T. Addressing the implementation problem in agricultural decision support systems: The example of vite.net. Comput. Electron. Agric. 2014, 100, 88-99. [CrossRef]

11. Seelan, S.K.; Laguette, S.; Casady, G.M.; Seielstad, G.A. Remote sensing applications for precision agriculture: A learning community approach. Remote Sens. Environ. 2003, 88, 157-169. [CrossRef]

12. Shibl, R.; Lawley, M.; Debuse, J. Factors influencing decision support system acceptance. Decis. Support Syst. 2013, 54, 953-961. [CrossRef]

13. McCown, R.L. Changing system's for supporting farmers' decisions: Problems, paradigms and prospects. Agric. Syst. 2002, 74, 179-220. [CrossRef]

14. Silver, M.S. Systems that Support Decision Makers: Description and Analysis; John Wiley Sons: New York, NY, USA, 1991.

15. Eastwood, C.; Klerkx, L.; Nettle, R. Dynamics and distribution of public and private research and extension roles for technological innovation and diffusion: Case studies of the implementation and adaptation of precision farming technologies. J. Rural Stud. 2017, 49, 1-12. [CrossRef]

16. Jakku, E.; Thorburn, P.J. A conceptual framework for guiding the participatory development of agricultural decision support systems. Agric. Syst. 2010, 103, 675-682. [CrossRef]

17. Rose, D.C.; Sutherland, W.J.; Parker, C.; Lobley, M.; Winter, M.; Morris, C.; Twining, S.; Ffoulkes, C.; Amano, T.; Dicks, L.V. Decision support tools for agriculture: Towards effective design and delivery. Agric. Syst. 2016, 149, 165-174. [CrossRef]

18. Kuhlmann, F.; Brodersen, C. Information technology and farm management: Developments and perspectives. Comput. Electron. Agric. 2001, 30, 71-83. [CrossRef]

19. Mackrell, D.; Kerr, D.; von Hellens, L. A qualitative case study of the adoption and use of an agricultural decision support system in the Australian cotton industry: The socio-technical view. Decis. Support Syst. 2009, 47, 143-153. [CrossRef]

20. GeoVisage. Available online: http:/ /geovisage.nipissingu.ca (accessed on 7 August 2017).

21. Bond, A. Farmers get ahead of Mother Nature. Available online: http:/ / yourontarioresearch.ca/2016/04/ getting-ahead-mother-nature/ (accessed on 7 August 2017).

22. Nipissing News. GeoVisage Tool Helping Farmers Grow, Now Online. Available online: http://www. nipissingu.ca/about-us/newsroom/Pages/GeoVisage-tool-helping-farmers-grow,-now-online.aspx (accessed on 7 August 2017).

23. HOBOlink. Available online: https://www.hobolink.com/ (accessed on 7 August 2017). 
24. Nittel, S.; Bodum, L.; Clarke, K.C.; Gould, M.; Raposo, P.; Sharma, J.; Vasardani, M. Emerging Technological Trends likely to Affect GIScience in the Next 20 Years. In Advancing Geographic Information Science: The Past and Next Twenty Years; Onsrud, H., Kuhn, W., Eds.; Global Spatial Data Infrastructure Association (GSDI), 2015. Available online: http://gsdiassociation.org/index.php/49-capacity-building/publications/343-advancinggeographic-information-science-the-past-and-next-twenty-years.html (accessed on 7 August 2017).

25. Hogan, P. NASA World Wind: A planetary visualization tool. In Proceedings of the ACM SIGGRAPH 2005 Educators Program, Los Angeles, CA, USA, 31 July-4 August 2005. [CrossRef]

26. Zhang, C.; Kovacs, J.M. The application of small unmanned aerial systems for precision agriculture: A review. Precis. Agric. 2012, 13, 693-712. [CrossRef]

27. Han, W.; Yang, Z.; Di, L.; Mueller, R. CropScape: A web service based application for exploring and disseminating US conterminous geospatial cropland data products for decision support. Comput. Electron. Agric. 2012, 84, 111-123. [CrossRef]

28. Mueller, R.; Harris, M. Reported uses of CropScape and the national cropland data layer program. In Proceedings of the International Conference on Agricultural Statistics VI, Rio de Janeiro, Brazil, 23-25 October 2013.

29. Du, W.; Chen, N.; Yan, S. Online soil moisture retrieval and sharing using geospatial web-enabled BDS-R service. Comput. Electron. Agric. 2016, 121, 354-367. [CrossRef]

30. Chen, N.; Zhang, X.; Wang, C. Integrated open geospatial web service enabled cyber-physical information infrastructure for precision agriculture monitoring. Comput. Electron. Agric. 2015, 111, 78-91. [CrossRef]

31. Georg, R.; Kruse, R.; Schneider, M.; Wagner, P. Visualization of agriculture data using self-organizing maps. In Applications and Innovations in Intelligent Systems XVI; Allen, T., Ellis, R., Petridis, M., Eds.; Springer: New York, NY, USA, 2009; pp. 47-60.

32. Kubicek, P.; Kozel, J.; Stampach, R.; Lukas, V. Prototyping the visualization of geographic and sensor data for agriculture. Comput. Electron. Agric. 2013, 97, 83-91. [CrossRef]

33. Tayyebi, A.; Meehan, T.D.; Dischler, J.; Radloff, G.; Ferris, M.; Gratton, C. SmartScape ${ }^{\mathrm{TM}}$ : A web-based decision support system for assessing the tradeoffs among multiple ecosystem services under crop-change scenarios. Comput. Electron. Agric. 2016, 121, 108-121. [CrossRef]

34. Batte, M.T.; Arnholt, M.W. Precision farming adoption and use in Ohio: Case studies of six leading-edge adopters. Comput. Electron. Agric. 2003, 38, 125-139. [CrossRef]

35. Denzin, N.K. The Sage Handbook of Qualitative Research, 3rd ed.; Lincoln, Y.S., Ed.; SAGE: Thousand Oaks, CA, USA, 2005.

36. Yin, R.K. Case Study Research: Design and Methods, 4th ed.; SAGE: Thousand Oaks, CA, USA, 2009.

37. Atlas.ti: Qualitative Data Analysis. Available online: http:/ / atlasti.com/ (accessed on 7 August 2017).

38. Zhang, C.; Walters, D.; Kovacs, J. Applications of low altitude remote sensing in agriculture upon farmers' requests: A case study in Northeastern Ontario, Canada. PLoS ONE 2014, 9, e112894. [CrossRef] [PubMed] 